\title{
DIREITOS HUMANOS E EDUCAÇÃO; EDUCAÇÃO EM DIREITOS HUMANOS: O INÍCIO DE UMA (IM)POSSÍVEL E (SUR)REAL PROTEÇÃO DO SER HUMANO
}

Felipe Bley Folly ${ }^{1}$

\section{RESUMO}

O presente artigo busca encontrar uma nova razão de ser da aplicação dos Direitos Humanos. Estes utilizados para produzir a emancipação e a humanização das relações internacionais e inter-individuais.

Para que tal objetivo possa ser alcançado, um dos principais pressupostos é a refundação do entendimento e aplicação do modelo educacional. Em primeiro lugar, a educação voltada à alteridade, à construção de um contato com o outro. Pois, só a partir do reconhecimento do próximo será possível entender e lutar pelos Direitos Humanos.

Um modelo educacional que possibilite a formação de um conhecimento voltado para a solidariedade, e não para a escravidão da modernidade, que vê no conhecimento uma forma de dominação. A partir de então, será possível analisar os Direitos Humanos como uma forma de defesa dos seres humanos, em especial, dos excluídos pela globalização hegemônica.

Outro ponto a ser discutido é o dos diálogos interculturais, a partir de uma hermenêutica diatópica, responsável por esclarecer que cada cultura é, de fato, incompleta. Da mesma forma, a compreensão das diferenças culturais poderá gerar uma ajuda recíproca no que tange a proteção dos Direitos Humanos.

Enfim, as reflexões a seguir buscam reinterpretar, refundar a noção de proteção dos Direitos Humanos, a partir da Educação, que é a responsável pela formação dos protegidos por estes direitos.

\footnotetext{
${ }^{1}$ Acadêmico do 4ํano da Faculdade de Direito da Universidade Federal do Paraná e membro de Núcleo de Estudos em Direito Internacional da Universidade Federal do Paraná. $<$ fbfolly@yahoo.de>
}

Revista Brasileira de Direito Internacional, Curitiba, v.3, n.3, jan./jun.2006 


\section{ABSTRACT}

The current article seeks a new meaning for the application of the Human Rights. These Rights could be aimed to produce, to ensure the emancipation and humanization of the international and individual relations.

For reaching this goal, one of the highest budgets is restablishing the comprehension about the educational model. First of all, the education should be connected with the difference, with the construction of a new someone else's contact. Therefore, with the next acknowledgment will be possible understand and fight for the Human Rights.

An educational model that enables the conception of a new knowledge connected with the solidarity, and not with the modern slavery, that understands the knowledge, as if it was a sort of domination. Subsequently, it will be possible to understand the Human Rights as a human beings' defense form, specially, for those who are excluded by the hegemonic globalization.

Another issue must be discussed: the intercultural dialogues, focusing a diatopical hermeneutics, responsible for enlightening that each culture is itself, indeed, sketchy. In the same way, the comprehension of cultural differences could engender a reciprocal helping about Human Rights protection.

Finally, the following reflexions try to build another concept of Human Rights protection, mainly since Education, which is responsible for the formation of those who are protected by these rights.

PALAVRAS-CHAVE: DIREITOS HUMANOS - PROTEÇÃO DOS DIREITOS HUMANOS - EDUCAÇÃO EM, PARA E A PARTIR DOS DIREITOS HUMANOS.

KEY WORDS: HUMAN RIGHTS - PROTECTION OF HUMAN RIGHTS EDUCATION IN, FOR AND SINCE HUMAN RIGHTS.

Revista Brasileira de Direito Internacional, Curitiba, v.3, n.3, jan./jun.2006 
“... Não esperes que o rigor de teu caminho Que teimosamente se bifurca em outro, Tenha fim.'2

(Jorge Luis Borges. In.: Elogio da Sombra)

\section{INTRODUÇÃO}

O fragmento acima, retirado do poema Laberinto do grande literato argentino, revelou-se apropriado após os meses de discussões ocorridos no grupo de estudos Mecanismos Internacionais de Proteção dos Direitos Humanos, do Núcleo de Direito Internacional da UFPR. Apropriado porque foi durante os debates que notei como são singelos, ardis e complexos os, tão aclamados, Direitos Humanos.

Quando são discutidos tais direitos, muito se questiona a respeito da sua efetiva proteção. Como fazê-la? Contra quem? A favor de quem? É uma proteção sem barreiras, sem limites? Entretanto, as respostas a essas indagações são como os caminhos de Borges, formam labirintos e não se preocupam em achar saídas definitivas, não querem ter fim. E, sinceramente, isso é salutar, pois enriquece o debate a respeito de Direitos Humanos, e evita que eles façam parte do discurso do Poder, enquanto mero jogo de palavras ilusórias.

Por isso, como forma de colaborar no aprofundamento da compreensão dos Direitos Humanos, que possibilite uma posterior luta (consciente) pela proteção (efetiva) dos mesmos, é que este artigo buscará discutir, com a contribuição dos pensamentos de Luis Alberto Warat ${ }^{3}$ e Boaventura de Souza Santos ${ }^{4}$, como nós, através de uma pedagogia emancipatória, de um diálogo multicultural, podemos proteger e promover os Direitos Humanos.

\footnotetext{
${ }^{2}$ BORGES, J. L. Elogio da Sombra. São Paulo: Editora Globo, 2001.

3 WARAT, L. A. Educação, Direitos Humanos, Cidadania e Exclusão Social: Fundamentos preliminares para uma tentativa de refundação. Disponível em: <http://www.mec.gov.br/univxxi/pdf/warat.pdf> Acesso em: 14 jun. 2005.

${ }^{4}$ SOUSA SANTOS, B. de. Reconhecer para Libertar: Os caminhos do cosmopolitismo multicultural. Rio de Janeiro: Civilização Brasileira, 2003.
}

Revista Brasileira de Direito Internacional, Curitiba, v.3, n.3, jan./jun.2006 


\section{RELAÇÕES DESUMANIZADAS}

Durante todo o século XX prevaleceu a barbárie, o senso de inumanidade, que contribuíram para a formação de seres humanos cada vez mais relegados ao segundo plano, cercados de falsas perspectivas. Duas Guerras Mundiais, afirmadas pela História Oficial, assim como a ardente Guerra Fria, e centenas, milhares de outras Guerras, resultantes em genocídios, fizeram, sobretudo no mundo ocidental, desaparecer a esperança na emancipação da espécie humana, fizeram derrocar idéias concebidas com o tempo, como democracia, liberdade, cidadania. Enfim, século em que o ser humano percorreu caminhos de exclusão, responsáveis pela criação de uma desesperança quase congênita.

Chegamos, portanto, em um novo século, parcialmente conscientes de que precisamos superar essa letargia reinante, através de uma mobilização que volte a valorizar a nós mesmos, para que tenhamos esperança, força necessária para o homem. Conforme ensina WARAT:

\footnotetext{
Refundar e poder pensar a mesmidade desde o outro que está em mim para poder produzir o novo, conviver com o imprevisível e poder escutar meus próprios sentimentos, valores e esperanças. [...] Repensar tudo o que nos coloca em situações de discriminação, opressão, exclusão, seja no lugar do opressor ou do oprimido, do discriminado ou do discriminador.
}

Dessa forma, torna-se possível entender que a Educação para, e a partir dos Direitos Humanos e da Cidadania, poderá recolocar o ser humano no mundo, com base, inclusive, no cosmopolitismo, que segundo Boaventura, "é a solidariedade transnacional entre grupos explorados, oprimidos ou excluídos pela globalização hegemônica ${ }^{6}$ ". Mas, primeiramente, é necessário pensar nas condições que possibilitarão essa transnacionalização cultural, esse diálogo entre culturas distintas.

\footnotetext{
${ }^{5}$ WARAT. L. A. Op. Cit. pp. $7-8$.

6 SOUSA SANTOS, B. de. Reconhecer para Libertar: Os caminhos do cosmopolitismo multicultural. Rio de Janeiro: Civilização Brasileira, 2003. p. 437.
}

Revista Brasileira de Direito Internacional, Curitiba, v.3, n.3, jan./jun.2006 


\section{3 (RE)EDUCAÇÃO PARA OUTROS DIREITOS HUMANOS}

A educação deve levar em conta a complexidade racional e emocional do ser humano. A busca da sensibilização das pessoas, para que sintam e escutem suas próprias emoções. É um processo de educação que aceita o indivíduo em sua realidade, em sua vivência, envolvido por suas emoções.

Assim, o ser humano será autônomo e terá capacidade para construir a alteridade social livre de exclusões e discriminações. Entretanto, a viabilidade dessa prática dependerá da reconstrução de "um discurso de Direitos Humanos vistos como Direitos da Alteridade". ${ }^{7}$

Essa reconstrução passa, principalmente, pela refundação da Educação. Uma Educação que tenha sensibilidade em relação aos discriminados e às diferenças como um todo. O sentido de educar como "tirar para fora o que há no interior da alma humana". ${ }^{8}$ Um educar que acredite na diferença, que a cultive, que veja na alteridade uma responsabilidade mútua entre os indivíduos. A possibilidade de construir relações inovadoras, criativas com o outro, afinal, sem o outro não existimos, é o alter que move nossa vivência. Por isso, faz-se tão importante esse processo que constrói com base na diferença, seja em nosso microcosmo, seja nas relações internacionais.

Uma nova prática de Direitos Humanos será possível, portanto, com a derrocada da educação tradicional, detentora de verdades imóveis e, hipocritamente, eternas. Viciada em procedimentos falaciosos, que negam ao indivíduo a possibilidade do pensamento, da reflexão e, acima de tudo, de aplicação do saber à realidade e às relações com o próximo. Só assim eles serão vivenciados como "Direitos Humanos da diversidade, da alteridade ou mesmo da cidadania, que deve deixar de ser excludente da diversidade, genocida da diferença". 9

É também importante termos consciência de que nós somos parte dessa diversidade, na qual ocorre troca com o outro. Este visto como uma complexidade, que nos observa, nos compreende. É uma relação múltipla que

\footnotetext{
${ }^{7}$ WARAT, L. A. Op. Cit. p. 25.

${ }^{8}$ WARAT, L. A. Op. Cit. p. 31.

${ }^{9}$ WARAT, L. A. Op. Cit. p. 37.
}

Revista Brasileira de Direito Internacional, Curitiba, v.3, n.3, jan./jun.2006 
deve ser vivida, trabalhada. $O$ outro visto dentro da poética da diferença, e não como um termo politicamente correto, utilizado no discurso educacional normalizador que, na realidade, fala no "outro" como um objeto de produção, como a busca da mesmidade.

Com essa nova compreensão educacional é possível passar a vislumbrar uma Educação Participativa Desescolarizante:

Onde o mestre ajuda na medida em que aquele que quer aprender assume a própria responsabilidade sobre a sua vida, trabalha sobre a própria existência e a própria experiência para aprender. [...] De gente se aprende convivendo com gente. ${ }^{10}$

Assim, o modelo educacional (refundado) passa a ser visto como formador de um conhecimento-emancipação ${ }^{11}$, uma ferramenta que na mão dos excluídos possibilitará a transformação do colonialismo em solidariedade, e para isso os Direitos Humanos (agora, refundados) devem estar presentes, caracterizando o projeto cosmopolita ${ }^{12}$ do qual fala Boaventura.

\section{PROTEÇÃO DOS DIREITOS HUMANOS PELA (RE)EDUCAÇÃO}

A própria Declaração Universal dos Direitos Humanos, de 1948, já reconhecia a importância da educação e sua aproximação com a proteção dos Direitos Humanos. Consta em seu preâmbulo a percepção de que a efetivação destes direitos depende de uma intervenção educativa:

\footnotetext{
A Assembléia Geral proclama a presente Declaração Universal dos Direitos Humanos como ideal comum a atingir por todos os povos e todas as nações, a fim de que todos os indivíduos e todos os orgãos da sociedade, tendo-a constantemente no espírito, se esforcem, pelo ensino e pela educação, por desenvolver o respeito desses direitos e liberdades [...]. (Grifo do autor).
}

\footnotetext{
${ }_{11}^{10}$ WARAT, L. A. Op. Cit. p. 54.

11 SOUSA SANTOS, B. de. Reconhecer para Libertar: Os caminhos do cosmopolitismo multicultural. Rio de Janeiro: Civilização Brasileira, 2003. p. 437.

SOUSA SANTOS, B. de. Toward a new Common Sense. Law, Science and Politics in the Paradigmatic Transition. Nova York: Routledge, 1995. p. 25.

${ }_{12}$ Projeto cosmopolita como aquele que engloba discursos e práticas contra-hegemônicos, que envolvem os diálogos interculturais a respeito dos Direito Humanos, assim como noções nãoocidentais dos mesmos.
}

Revista Brasileira de Direito Internacional, Curitiba, v.3, n.3, jan./jun.2006 
Assim como no $26^{\circ}$ artigo da mesma Declaração, está previsto o direito à educação, em especial em seu $\S 2^{\circ}$, que afirma a idéia de uma educação que valorize os sentimentos humanos e a alteridade:

\footnotetext{
A educação deve visar à plena expansão da personalidade humana e ao reforço dos direitos do Homem e das liberdades fundamentais e deve favorecer a compreensão, a tolerância e a amizade entre todas as nações e todos os grupos raciais ou religiosos, bem como o desenvolvimento das atividades das Nações Unidas para a manutenção da paz.
}

Torna-se forte a idéia de que sem a Educação não se realizam, não se protegem os Direitos Humanos. E, certamente, a recíproca é verdadeira. É um desafio atingir essa concretização, ou seja, transformar as promessas legislativas em realidade, e para isso devemos atuar como modificadores no meio social. Um exemplo seria, no âmbito do Direito, a implementação da mediação preventiva nas práticas jurídicas, em que "os operadores tradicionais do Direito começam a rever suas funções, se descobrem numa atitude educativa e tomam consciência de que para esta postura pedagógica precisam respaldar-se em práticas de ajuda às partes dos conflitos através das quais as mesmas descubram a importância de escutar-se a si mesmas, seu direito a uma vida digna e suas possibilidades de ter direito aos seus próprios direitos". ${ }^{13}$ Surge a idéia da ecologia dos Direitos Humanos, ${ }^{14}$ ou seja, a relação destes direitos com os seres humanos e os meios social, econômico, moral, jurídico e político.

A Educação para os Direitos Humanos focada na educação para a paz, que entenda os conflitos como elementos do mundo, os quais podem ser resolvidos criativa e positivamente, sem a coerção, sem a violência estatal imposta por seus instrumentos policiais e judiciais. Uma educação voltada para a paz, que busque, inclusive, a compreensão dos conflitos desde a infância. Para isso é imprescindível a promoção de campanhas solidárias aos Direitos Humanos, que promovam a sensibilização para a diferença; realização de discussões e debates nas Escolas, abrangendo a comunidade ao seu redor.

\footnotetext{
${ }^{13}$ WARAT, L. A. Op. Cit. p. 94.

${ }^{14}$ Idem, ibidem.
}

Revista Brasileira de Direito Internacional, Curitiba, v.3, n.3, jan./jun.2006 
A comunidade baseada na diferença, na multiplicidade e na alteridade, passa a se reorganizar, uma reorganização comunitária, com base na luta e na educação pelos Direitos Humanos. Um combate liderado pelos excluídos, no caso da América Latina, pelos indígenas, pelos trabalhadores rurais, que vão em busca dos Direitos Humanos, de sua própria dignidade.

A Educação em Direitos Humanos deve estar preparada para ensinar estratégias de organização aos excluídos, que passem a se utilizar destes direitos em uma luta contra-hegemônica. E que assim, tornem-se (nós, que lemos este texto, estamos entre os excluídos), inclusive, gestores dos Direitos Humanos.

\section{DIREITOS HUMANOS REFUNDADOS E EMANCIPATÓRIOS}

Os Direitos Humanos surgem, então, como parte de um roteiro emancipatório, com iniciativas, organizações e movimentos que buscam combater, primordialmente, a discriminação, geradora das exclusões sociais. São atividades cosmopolitas, no que tange a solidariedade, como:

[...] diálogos e articulações Sul-Sul; novas formas de intercâmbio operário; redes transnacionais de lutas ecológicas, pelos direitos da mulher, pelos direitos dos povos indígenas, pelos direitos humanos em geral; serviços jurídicos alternativos de caráter transnacional; solidariedade anticapitalista entre o Norte e o Sul; organizações de desenvolvimento alternativo e em luta contra o regime hegemônico de propriedade intelectual que desqualifica os saberes tradicionais e destrói a biodiversidade. ${ }^{15}$

Esse caminho de emancipação a partir dos Direitos Humanos busca estabelecer diálogos interculturais, a respeito de preocupações em comum, mesmo que entre culturas distintas, como forma de superar a discussão do universalismo e do relativismo cultural. É preciso observar também, que "todas as culturas são incompletas e problemáticas nas suas concepções de dignidade humana. [...] A incompletude é mais facilmente perceptível do exterior, a partir da perspectiva de outra cultura"; ${ }^{16}$ por isso mesmo, a

\footnotetext{
15 SOUSA SANTOS, B. de. Reconhecer para Libertar: Os caminhos do cosmopolitismo multicultural. Rio de Janeiro: Civilização Brasileira, 2003. p. 436.

${ }^{16}$ Idem. p. 442.
}

Revista Brasileira de Direito Internacional, Curitiba, v.3, n.3, jan./jun.2006 
importância do diálogo intercultural, com base em Direitos Humanos abertos para a alteridade.

A proteção dos Direitos Humanos com base na transnacionalidade, com um diálogo constante, que resulta em uma infinidade de sentidos, tudo isso possibilita reafirmar a idéia defendida pelos iminentes pensadores, Warat e Boaventura, de Direitos Humanos Mestiços.

Seguindo o desenvolvimento da emancipação pelos Direitos Humanos, surge, como forma de estabelecer esse diálogo multicultural na defesa e proteção dos Direitos Humanos, a hermenêutica diatópica, já defendida por Boaventura, que tem como primordial objetivo, criar a consciência de incompletude cultural, consciência esta que ocorre a partir do diálogo estabelecido entre culturas diversas.

Esse diálogo diatópico é muito fraco, quiçá ausente, na cultura ocidental de Direitos Humanos, o que contribui, de fato, para uma ilusão de que nessa parte do mundo os direitos do homem são defendidos a todo tempo. Chega-se ao ponto de, em nome dos Direitos Humanos, aniquilar estes mesmos direitos; é a cruel realidade da inversão dos Direitos Humanos, praticada, reiteradamente, por líderes do capitalismo atual.

\footnotetext{
Los derechos humanos se transformaron en una agresividad humanitaria: violar los derechos humanos de aquellos que los violan. Detrás de esto hay otra convicción según la cual quien viola derechos humanos, no tiene derechos humanos. El violador de los derechos humanos es transformado en un monstruo, en una bestia salvaje, que se puede eliminar sin que haya la más mínima cuestión de derechos humanos. Pierde hasta el carácter de ser humano. ${ }^{17}$
}

Por mais complexa e imutável que se apresente essa realidade, é nosso dever refletir e propor "caminhos bifurcados" que possam ser uma forma de efetivar a proteção dos Direitos Humanos.

\footnotetext{
${ }^{17}$ HINKELAMMERT, F. J. La Inversión de los Derechos Humanos: El Caso de John Locke. In.: FLORES, J. H.(Ed.); HINKELAMMERT, F. J., RUBIO, D. S.; GUTIÉRREZ, G. EL VUELO DE ANTEO: Derechos Humanos y Crítica de la Razón Liberal. Bilbao: Desclée de Brouwer, 2000. p. 80.
}

Revista Brasileira de Direito Internacional, Curitiba, v.3, n.3, jan./jun.2006 


\section{CONSIDERAÇÕES FINAIS (DISTANTES DO FIM DO CAMINHO)}

Finalmente, é defensável, no que se refere aos Direitos Humanos, Direitos da Alteridade, a idéia de que a efetiva proteção destes começa com o direito ao conhecimento, o direito a um modelo educacional que respeite, acima de tudo, a integridade, a autonomia de cada ser humano, e que os inclua, libertariamente, na realidade social. Os Direitos Humanos vinculados a uma matriz educacional que nos permitirá criar espaços em que o direito a ter direitos poderá ser, constantemente construído.

É primordial também a defesa pela busca da alteridade, como forma de compreender quem somos nós mesmos. É também na alteridade que se encontram os meio para promover a organização comunitária, em que as subjetividades são, reciprocamente, consideradas. Dessa maneira, surge a possibilidade de intelecção da conflitividade entre os diferentes, permitindo-nos notar a relevância do auto-entendimento e da coesão social.

Da mesma forma, será possível estabelecer um diálogo intercultural no âmbito internacional. Diálogo construído com base no reconhecimento recíproco de que nenhuma cultura é melhor, ou mais completa e justa do que outra, mas que na verdade todas podem, e devem, discutir mutuamente suas virtudes e falhas, com a intenção de cultivar os Direitos Humanos internacionalmente. Tornando-se possível aprimorar órgãos internacionais responsáveis, acima de tudo, pela proliferação de uma consciência humanista e libertária, que torne realidade a defesa dos Direitos Humanos na vida de cada indivíduo. É importante ressaltar também a função dos regimes internacionais de aplicação e proteção de Direitos Humanos, como o europeu, o interamericano, o africano e o asiático, na efetivação dos Direitos Humanos, a partir do momento em que atuam como fiscalizadores, guardiões dos direitos dos homens e mulheres, em especial, dos marginalizados pela sociedade, da maioria, chamada de minoria.

Uma reestruturação do ser humano que leva a um novo entendimento e a uma nova compreensão do que são os Direitos Humanos. Mesmo porque, essa reestruturação é feita através destes próprios direitos. Passamos a buscá- 
los como direitos nossos, que se desenvolvem entre nós, e nos possibilitam alçar um diálogo, sem medo das diferenças, sem medo da alteridade. Enfim, Direitos Humanos em sua função pedagógica como forma de proteção, e não como mero instrumento do Estado.

Direitos Humanos e Educação como propulsores: I) da formação de professores em Direitos Humanos; II) da busca de uma polícia que seja, antes de tudo, comunitária, que tenha como meta a mediação preventiva, e não o simples uso da violência; III) do incentivo para a participação da comunidade, como aquela que deve exigir o cumprimento de seus direitos assegurados constitucionalmente, ou seja, uma ação comunitária positiva.

Assim, reconheceremos os Direitos Humanos como algo menor, porém, valioso, que se desenvolve, especialmente, em nossos diálogos como seres humanos libertos. E, ao mesmo tempo, Direitos Humanos como mediadores em conflitos internacionais, aplicados, também, através de diálogos.

Resta-nos, então, reconhecer a utopia que envolve a luta e proteção dos Direitos Humanos, e seguirmos pelos caminhos e suas bifurcações, nos dizeres sábios de Borges, sem medo de não chegar a um fim, mas com a (quase) certeza de que poderemos mudar algo, nem que somente a nós mesmos, o que representa o começo de novas relações humanas, o começo no outro.

\section{REFERÊNCIAS}

BORGES, J. L. Elogio da Sombra. São Paulo: Editora Globo, 2001.

HINKELAMMERT, F. J. La Inversión de los Derechos Humanos: El Caso de John Locke. In.: FLORES, J. H.(Ed.); HINKELAMMERT, F. J., RUBIO, D. S.; GUTIÉRREZ, G. El Vuelo de Anteo: Derechos Humanos y Crítica de la Razón Liberal. Bilbao: Desclée de Brouwer, 2000.

SOUSA SANTOS, B. de. Reconhecer para Libertar: Os caminhos do cosmopolitismo multicultural. Rio de Janeiro: Civilização Brasileira, 2003.

Revista Brasileira de Direito Internacional, Curitiba, v.3, n.3, jan./jun.2006 
WARAT, L. A. Educação, Direitos Humanos, Cidadania e Exclusão Social:

Fundamentos preliminares para uma tentativa de refundação. Disponível em : <http://www.mec.gov.br/univxxi/pdf/warat.pdf> Acesso em: 14 jun. 2005.

Revista Brasileira de Direito Internacional, Curitiba, v.3, n.3, jan./jun.2006 